\title{
DERLEME
}

\section{Sağlık Alanında Elektronik Öğretim Yöntemleri}

Gülsüme SATIR ${ }^{1}$, Nezihe KIZILKAYA BEJI'

\section{ÖZ}

Öğrenmek, değişim ve gelişmektir. Günümüzde mobil teknolojilerin ilerlemesi ile birlikte elektronik öğrenme (eöğrenme) önemli ve vazgeçilmez bir durum haline gelmiştir. Bilgi ve iletişim teknolojilerindeki gelişmeler sağlik alanında eğitim gören öğrencilere farklı eğitim olanakları sağlamaktadır. Özellikle internet ve bilgisayar sistemlerinde yaşanan hızlı gelişim eğitimde dönüşüm meydana getirmiştir. Elektronik Öğrenme (E-Öğrenme), Artırılmış Gerçeklik (AG), Sanal Gerçeklik (SG), Yapay Zeka, Bulut Bilişim, QR Kod ve Simülasyon gibi uygulamalar eğitimde kullanılan yenilikçi ve farklı uygulamalardır. Bu uygulamalar öğrenciler için farklı öğrenme seçenekleri sunmaktadır. Elektronik Öğrenme ile öğrenciler ders içeriklerine istediği yer ve zamanda ulaşabilmektedir. Bu derlemede sağlık alanında kullanılan farklı elektronik öğretim yöntemleri incelenmiştir.

Anahtar Kelimeler: Öğrenme; Öğretim; Să̆lık Alanı

\section{Electronic Teaching Methods in The Field of Healthcare}

Gülsüme SATIR ${ }^{1}$, Nezihe KIZILKAYA BEJI'

\begin{abstract}
It is learning, change and development. Electronic learning (e-learning) has become a critical and indispensable situation with the advancement of mobile technologies. Developments in information and communication technologies provide different educational opportunities to students studying in the field of health. Especially the rapid development in internet and computer systems has transformed education. Applications such as Electronic Learning (E-Learning), Augmented Reality (AR), Virtual Reality (VR), Artificial Intelligence, Cloud Computing, QR Code and Simulation are innovative and different applications used in education. These applications offer different learning options for students. With Electronic Learning, students can access course contents whenever and wherever they want. In this review, different electronic teaching methods used in the field of health are examined.
\end{abstract}

Keywords: Education; Health Field; Learning

\footnotetext{
${ }^{1}$ Biruni Üniversitesi, Sağlık Bilimleri Fakültesi Ebelik Bölümü, İstanbul, Türkiye

${ }^{2}$ Biruni Üniversitesi Sağlık Bilimleri Fakültesi Hemşirelik Bölümü, İstanbul, Türkiye Sorumlu Yazar: Gülsüme SATIR

E-posta adresi: gsatir@biruni.edu.tr $\quad$ ORCID No: 0000-0003-1314-8488 Gönderi Tarihi: 23.03.2021 


\section{GíRiş}

Öğrenmek, değişim ve gelişmektir. Öğrenmek kişiliğimizi biçimlendiren değer, inanç ve düşüncelerimizin fark ederek olaylara, bireylere değişik pencerelerden bakabilmek ve dünyayı daha iyi kavrayabilmek için kendimizi yetkin birey haline getirmektir. Öğrenme, bireyin bir anlamda değişimidir ve bireyseldir. Birey istediği ve değişim için hazır bulunduğu zaman öğrenme gerçekleşir (1).

19. yüzyılda ilk olarak mektupla eğitim olarak uzaktan öğrenme uygulamaları başlamıştır. Ülkemizde 1996 yılında ODTÜ (Orta Doğu Teknik Üniversitesi) sertifika programı ile öncülük etmiştir (2). Günümüzde mobil teknolojilerin artması ile elektronik öğrenme (e-öğrenme) önemli hale gelmiştir. Öğrenme içerik ve materyallerinin elektronik ortamda paylaşılmakta ve öğrenciler istediği yer ve zamanda erişebilmektedir.
Eğitmenler ve öğrenciler ile etkileşimde olabilmektedirler. E-öğrenmenin (elektronik öğrenme) avantajları; maliyeti azaltır, öğrencilerin ilgilerini arttırır ve eğitim gereksinimleri için kolaylaştırıcıdır (3).

Konuya öğrenci açısından bakıldığında cinsiyet, eğitim düzeyi, hazırbulunuşlukları internete erişim durumu, akı1lı telefona sahip olma durumu gibi kavramlar e-öğrenmenin etkili biçimde uygulanmasında önemli faktörlerdir (4). Geri bildirimin gecikmesi ve gerçek zamanlı bilginin kullanılamaması e-öğrenmenin dezavantajlarındandır (5). Fiziki ve maddi koşulların yetersizlikler sebebiyle uzaktan eğitim uygulamalarına yönelim kaçınılmaz bir zorunluluk olmaktadır (6). Aşağıda sağlık alanında kullanılan elektronik öğrenme yöntemleri ele alınmıştır.

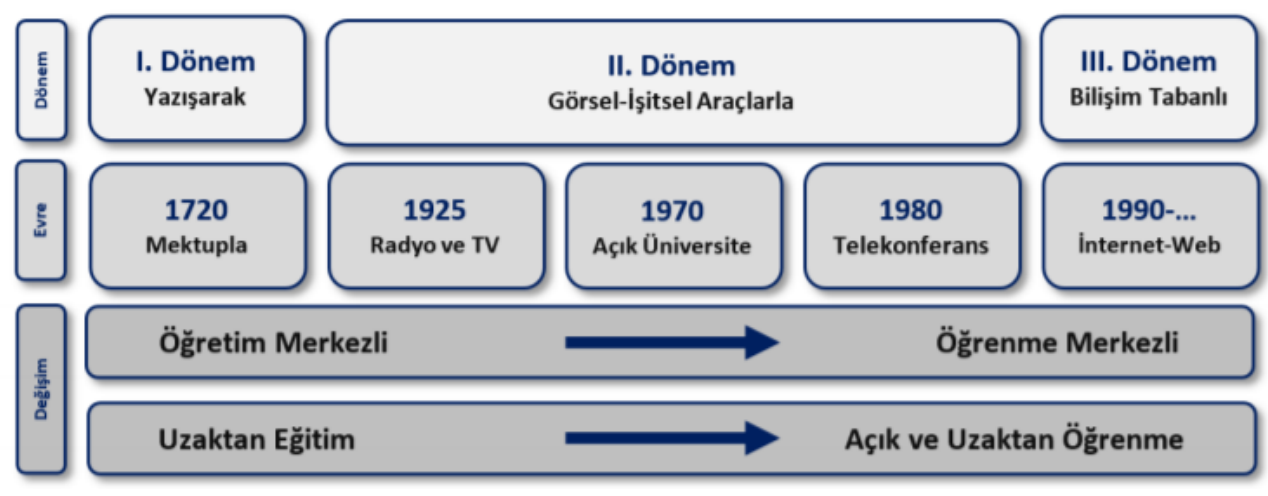

Şekil 1: Eğitimde açık ve uzaktan öğrenmeye doğru yaşanan değişim (7). 


\section{Artırılmış Gerçeklik (AG)}

Dünya ile etkileşim öğrenme sürecinde önemlidir ve AG bu etkileşimi kolaylaştırmanın en iyi yollarından biridir (8). Artırılmış gerçeklik uygulamaları ile 3 boyutlu çalışmak öğrenci motivasyonu ve katılımını arttırmaktadır (9). Yapılmış bir çalışmada artırılmış gerçeklik ile eğitim verildiğinde öğrencilerin başarısına olumlu etki ettiği belirtilmiştir (10).

AG, gerçek ve sanal nesneleri birleştiren sürükleyici bir uygulamadır. Farklı öğrenme ortamları yaratır, gerçek dünyada mümkün olmayan olayları öğrencilerin deneyimlemelerini sağlar. Ayrıca bilgi ve beceriler AG teknolojisi ile daha etkin bir şekilde geliştirilebilir, düşünme becerilerini teşvik edebilir, soyut kavramların anlayışını artırabilir $(8,9)$.

Dezavantajları ise bazı öğrenciler teknik sorunlar yaşayabilir ve bazı öğrenciler bu teknolojiyi karmaşık bulabilir. AG uygulamalarının temel zorluklarından biri kullanılabilirliktir; bununla birlikte, kullanım kolaylığı da bir avantaj olarak bildirilmektedir. Kullanılabilirlik sorunlarının doğrudan AG teknolojisi ile ilgili olduğunu ve bunun yerine yetersiz teknoloji deneyiminden, ara yüz tasarım hatalarından, teknik sorunlardan veya olumsuz tutumlardan kaynaklanabileceğini gösteren kanıt yoktur (8).

Gerçek ve sanal nesnelerin kombinasyonu, öğrenciler sanal ve gerçeklik arasında iken zorluk çekebildikleri için karışıklığa neden olabilir. AG teknolojisinin bir öğrenme ortamında kullanılması, öğrencilerin karmaşı görevleri yerine getirmek için büyük miktarlarda bilgi ve çoklu teknolojik cihazlarla etkileşime girmesi gerektiğinden çoklu görev gerektirir. Bu, bilişsel aşırı yüklenmeye ve şaşkınlık hissine neden olabilir. Eğitimciler AG’yi kullanma konusunda isteksiz olabilirler çünkü bu teknoloji genellikle yenilikçi öğretim yaklaşımlarının uygulanmasını gerektirir (5). AG uygulamaları aracılığıyla mevcut olan içerik genellikle esnek değildir, bu da öğretmenin içerik üzerindeki kontrolünü kısıtlar ve öğrenci ihtiyaçlarını karşılamak için adaptasyonu önler. Başka bir zorluk, mobil AG teknolojisinin istikrarının garanti edilmemesi olabilir, kullanıcılar ayrıca AG teknolojisini tanımak için zamana ihtiyaç duyabilir (8). 


\section{Sanal Gerçeklik (SG)}

Sanal gerçeklik (SG) "Kullanıcıların bilgisayar tarafindan oluşturulmuş üç boyutlu bir benzetim içinde otantik dünyaya ilişkin bir durumu, vücutlarına giydiği özel aygıtlarla duygusal olarak algılayıp bu yapay dünyayı etkin olarak deneyimleyebildiği sistemlerdir.” (11). Karmaşık konuları anlamlı kılma ve soyut kavramları 3 boyutlu hale getirerek somutlaştırdı̆̆ 1 için öğrenmeye katkı sağlamaktadır (12). Sanal gerçeklik uygulamasının diğer grafiksel çoklu ortam uygulamalarından ayıran üç ana özelliği bulunmaktadır. Bunlar;

Gezinme: Sanal gerçeklik ortamlarında yaygın şekilde olarak görülür. Uzamsal farkındalığ 1 destekleyerek uzak mesafeler arasında verimli ve rahat hareket imkanı sağlar. Böylece kullanıcı esas görevine odaklanabilmektedir.

Etkileşim: Kullanıcı ve çevre arasındaki etkileşim eş zamanda meydana gelir. Üç boyutlu nesnelerle aynı zamanda gerçekleşen etkileşim, kullanıcıda var olma hissi yaratmaktadır.

Sürükleme: Sürükleme kullanıcının duyguları anlamına gelmektedir. Sanal gerçeklik ile betimlenen ortamda olma duygusunu hissetme ve bu ortamda hareket etme yeteneğidir. Kullanan kişi dış ortamdan soyutlanır.

Sanal gerçeklik uygulamasında kullanıcılar, ekranlı gözlük, elektronik eldiven ve sensörlere sahip giysi ile içinde bulundukları ortamın etkileşimli bir parçası olurlar (13). Tıp eğitiminde öğrenciler sanal kadavralar ile çalışabilmektedir. Sanal gerçeklik laboratuvarlarında öğrenciler gerçekleştirilmesi tehlikeli ve maliyetli deneyleri defalarca yapabilme şansı bulabilmektedir.

Uygulamanın dezavantajları ise; maliyetlerinin yüksek olması, gerçekliğin yeteri kadar sağlanamaması, erişim imkanlarının kısıtlılı̆̆ eğitim faaliyetlerine uyarlanmasının uzmanlık gerektirmesi, kullanımının zor olması ve teknik bilgi gerektirmesi sayılabilir fakat kullanım avantajları göz önünde bulundurulduğunda bu sınırlılıkların ortadan kalkacağı düşünülmektedir $(11,14)$.

Sanal gerçeklik uygulamalarının eğitimdeki avantajları;

- Öğrencilerin dersi anlaması için daha iyi ortam sağlayabilir.

- Öğrencilerin yaratıcılık yeteneklerini ve özgüvenlerini artırabilir. 
- Öğrenenlerin inceleme ve keşfetme olanakları olmadığında öğrenen kişilere kolaylıklar sağlayabilir.

- Motivasyonlarına olumlu katkı sağlayabilir.

- Dişarıdan gelen uyaranlardan soyutlandığı için sadece üzerinde çalışılan bilgiye odaklanılmasını sağlayabilir.

- Oluşturulmasına firsat olmayan ortamların oluşturarak, öğrencilerin deneyim yaşamalarına olanak sağlayabilir.

- Kişiler öğrenme performansına göre defalarca uygulamalara katılabilir.

- Öğrenenler yaşayarak öğrenebilirler.

- Gerçek yaşam etkinlikleri sırasında karşılaşılabilecek risk faktörleri belirlenecektir $(11,15)$.

- Var olma duygusu ile öğrenme sürecine destek olabileceği belirtilmiştir (16).

Sanal gerçeklik uygulamasının çıkışı ilk zamanlarda eğlence olarak görülmekteydi. Fakat, günümüzde tıpta cerrahi eğitim, ameliyat simülasyonu, görselleştirilmesi zor olan tüm derslerin anlatımında yaygın bir şekilde kullanılmaktadır. Bu uygulama ile uygulayıcılar fiziki ortam ile etkileşimde bulunmadığı için daha güvenli eğitim alabilmektedirler (17). Son yıllarda hasta güvenliğini ve hasta bakımını iyileștirmek için sanal gerçeklik teknolojilerinin kullanımı artmıştır. Öğrenciler hastanede gibi hissederek, hastaya zarar vermeden tedavi etme, takım çalışması, klinik karar verme yeteneklerini geliştirebilmektedir. S1klıkla deneyebildikleri için profesyonel cerrahi beceriler edinmelerinde önemli bir firsat sağlamaktadır (18). Tıp eğitimde öğrencilerin kadavrasız cerrahi işlemler yapmasını ve anatomiyi öğrenmesine bir alternatif olarak görülmektedir (19). Öğreticilerde öğrencilerini bu uygulama ile değerlendirmektedir (18).

\section{Yapay Zeka}

Yapay zeka 1956 y1lında gündeme gelmiştir fakat John McCarthy kavramın mucidi olarak kabul edilmektedir. McCarthy yapay zekayı "insan benzeri zeki makineler özellikle de zeki bilgisayar programları yapma bilimi ve mühendisliğii" tanımlamıştır (20). Başka bir tanımı ise öğrenme, uyarlama, sentezleme gibi insan benzeri süreçlerle ilgilenebilen bilgi işlem sistemleridir (21).

Günümüzde sıklıkla duyduğumuz Siri gibi kişisel asistanlar, anında gerçekleşen dil çevirileri, akıllı eğitim düzenleme mekanizmaları, sanal sınıflar, 
yüz ve örüntü tanıma, robotik cerrahi gibi uygulamalar yaşamımızı kolaylaştırmaktadır. Yapay zeka uygulamaları aralıksız geliştirilmekte ve güncellenmektedir $(21,22)$.

Yapay zeka, ilgilendiği alanlar bakımından veri tabanlı, mantık tabanlı ve bilgi tabanlı olarak değişiklik göstermektedir. Eğitimsel uygulamalar 1980-2000 yılları arasında genelde bilgi tabanlı yaklaşım ile sürdürülmekteydi. Bugün ise kişiselleştirilmiş eğitim veya diyalog eğitim sistemleri, makale analizleri, ölçme-değerlendirme sistemleri, otomatik test oluşturma sistemleri bulunmaktadır. $\mathrm{Bu}$ alanlar sıklıkla öğrenmeyi desteklemektedir (20). Eğitimde, teori ile teknolojiyi bütünleştirerek büyük bir değişime yol açtığ 1 ve bu ilerlemenin öğretim sürecinde devamlı olacağ́1 görülmektedir. Yapay zeka ile ilerleyen zamanlarda sirasiyla;

- Öğretim boyunca öğrencilere yapay zeka ile birebir ve etkin destek verilebilir,

- Ölçme ve değerlendirme öğrenciler ve öğreticiler için yeni boyut haline gelebilir,

- Bireyselleştirilmiş öğrenme yaygın olabilir,
- Eğitimde çok önemli yeri olan dönüt yapay zeka ile öğrencilerin ihtiyaçlarına göre otomatik hale gelebilir (20).

Hızla ilerleyen yapay zeka, eğitimi güçlendireceği ve öğrenim sürecinde yaşanılan sorunların azaltılmasında büyük bir etki yaratacağı düşünülmektedir (20). Yüksek öğretim, yapay zekadan birçok yönden etkilenecektir. Özellikle müfredat ve öğrencilerin kayıt sürecinin etkileneceği düşünülmektedir. Yapay zeka hızlıdır ve tutarlıdır. Fakat yaratıcılık, yenilikçilik, eleştirel düşünme, problem çözme, sosyalleşme, liderlik, empati, işbirliği ve iletişim gibi becerilerde hala eksikliği bulunmaktadır (23).

\section{Bulut Bilişim}

Bilişim teknolojileri açısından bulut, interneti temsil etmektedir. Bulut bilişim, bilgisayar hizmetlerinin kullanıcı isteği ile ağ üzerinden cihaz yardımıyla sunulduğu bilişim hizmetidir (24). Amacı, donanım ve yazılım imkanlarının herkes tarafından kolay ve ucuz olarak kullanılmasıdır. Verinin işlenmesi, bilgi ve belgelerin kullanılması bulut bilişim sayesinde daha kolay hale gelmiştir (25). Örneğin, Google Dokümanların varlığ sayesinde birden fazla kişi aynı dosya üzerinde 
çalışma olanağına sahip olabilmektedir.

Kullanıcılar internet ağı olan herhangi bir mekandan bilgisayar veya mobil cihaz yardımıyla bu belgelere erişebilmekte değişiklik yapabilmektedir. $\mathrm{Bu}$ özellikler grup çalışmaları için yarar sağlamaktadır (26).

Çin'de BlueSky uygulaması kullanılmaktadır. Elektronik öğrenme platformu olan bu uygulama, eğitim hizmetlerinin daha çok bireye ulaşarak, az gelişmiş bölgelerin eğitim ihtiyacını karşılayarak gelişmiş bölgelerle arasındaki farkın ortadan kalkması istemektedir. BlueSky'ın diğer avantajları ise okullarda yüz yüze verilen eğitime katk1 sağlamak, bilgi paylaşımı ve işbirliği olarak belirtilmektedir.

Demirkaya ve Sarpel'in (2018) lisans öğrencileri ile yaptığı çalışmasında, bulut bilişimin bireysel ve grup çalışmalarında öğrenmeyi ve öğrenci performansını artırdığını ve grup çalışmasında bulut bilişimin kullanılabileceği sonucuna ulaşmışlardır (27).

\section{QR Kod (Quick Response- Hızlı Cevap)}

QR kodu, bir mobil cihaz kullanılarak taranan ve kullanıcının bir web adresi girmeden doğrudan bir web sitesine bağlanmasını sağlayan iki boyutlu bir barkod türüdür (28). QR kod görsel veri şifreleme yöntemidir. QR kod Toyota'nın üretim ve imalat sırasında kullanılan materyallerin etiketlenerek, üretimi daha verimli hale getirilmesi sebebiyle bulunmuştur. Toyota 2010'da patent haklarını kişilerin kullanımına ücretsiz olarak sunmuştur. QR kodlarının özellikleri ise;

- Geleneksel barkodlara oranla dikey ve yatay veri depoladığı için on kat az yer tutar.

- Kirlense ya da kısmi bir şekilde yırtılması durumunda işlevlerine devam ederler.

- 360 derece ve hizlı okuma kapasitesi bulunmaktadır (29).

Çoğu akıllı telefon QR kod tarama yazılımı önceden yüklenmiş olarak gelmemektedir; bu nedenle, öğrencilerin uygun indirmesi ve yüklemesi gerekir. Uygulamalar iTunes veya Play Store gibi yerlerden ücretsiz olarak indirilebilir (30).

Mobil cihazlar, sistemler ve teknolojiler artık evrensel olarak sahipleniliyor, kabul ediliyor ve kullanılıyor. Sonuç olarak, öğrenmenin anlamı ve önemi de değişiyor. Mobil teknolojiler, öğrenmedeki bu değişikliklere yanıt verebilir. Araştırmacılar ve eğitimciler, mobil teknolojilerin 
öğrenme araçları olarak potansiyelinin farkına vardılar ve mobil teknoloji yeni bir öğrenme stili olan mobil öğrenmeyi teşvik etti. Mobil teknolojiler sınıf dışında öğrenmeyi kolaylaştırır ve öğrenme materyalleri artık ders kitaplarıyla sınırlı kalmamasını sağlamaktadır (31).

QR kodları, öğrencilere elektronik materyallerde yol göstermenin basit ve ucuz bir yoludur. Öğretme ve öğrenmeyi desteklemek için çevrimiçi multimedya ve destekleyici materyallere anında erişim sağlarlar (30).

Eğitimde QR kodlar gerçek dünya ve dijital dünya arasında köprü görevi görmektedir (32). Kitap, poster gibi materyallerinin üzerine yerleştirmek, öğrencilerin kayıt işlemlerini gerçekleştirmek, anket uygulamalarına yer vermek, ölçme ve değerlendirme süreci için kullanılabilmektedir (33). Ayrıca e-postalara yönlendirilen öğrenenler, eğiticileri ve akranlarıyla bilgi paylaşımı yapabilirler. Bu sayede öğrenmede esneklik ve bireysellik sağlanabilir. Çevrimiçi öğrenme kaynakları ile öğrenenin motivasyonunu ve başarısını arttırmak da mümkün olmaktadır (32). Bu uygulama öğrencilere neyi ve nasıl öğrendikleri konusunda özerklik sağlar ve öğrenci merkezli bir öğrenme yaklaşımını benimser. Ayrıca, öğrencilerin içsel motivasyonunu artırmaya yardımcı olabilir (34).

Zaman ve mekan sınırını ortadan kaldırarak öğrenen ve eğitici arasındaki iletişimi sınıf dışına taşır, öğrencilerin gelecekteki kariyerlerinde ihtiyaç duyacakları becerileri geliştirmelerine yardımcı olur, öğrenmeyi destekleme ve öğrencilerin öğrenme sürecine daha fazla dahil olma motivasyonunu artırma yetenekleri bulunmaktadır. QR kodlarının ana avantajları hızları, okunabilirlikleri ve geniş depolama kapasitesidir. Bilgilere mobil cihazlardan kolayca erişilebilir ve kullanıcıları klavye giriş hataları sorunundan kurtarabilir (35). Tıp öğrencileri için anatomi eğitimi sağlar (28). QR hemşirelik ve ebelik eğitiminde de büyük bir potansiyele sahiptir çünkü öğrencilerin geleneksel öğretim materyallerine kıyasla kaynaklara daha kolay ve verimli bir şekilde erişmesine olanak tanır $(30,35)$. İlaç etiketlerine yerleştirilen QR kodları, öğrencileri ilaçla ilgili uygun bilgilere yönlendirebilir ve öğrencileri uygulamadan önce ilacı araştırmaya teşvik edebilir. Kalıcı kateter kitlerinin üzerine yerleştirilen kodlar, öğrencileri 
doğru yerleştirme tekniğini gösteren eğitmen tarafindan oluşturulan bir YouTube videosuna bağlayabilir (36).

QR kodlarını öğrenciler, güvenilir ve kullanımı kolay olarak tanımlamaktadır (37). Öğrenciler, barkod etkinliğinin öğrenme ihtiyaçlarını karşıladığını, sınava daha iyi hazırlanmalarına yardımcı olduğunu, değerli bir etkinlik olduğunu ve sınavdaki performanslarına yardımcı olduğunu hissederler (38). Yapılan çalışmalarda bu barkod etkinliğinin öğrenciler için ilgi çekici, etkileşimli bir sınıf etkinliği olduğu görülmüştür $(28,38)$.

\section{Simülasyon}

Simülasyon 1970 yılına kadar havacılık alanında kritik becerileri öğretmede kullanılmıştır. Son yıllarda ise sağlık alanı öğrencilerinin eğitiminde önemli bir öğretim arac1 olmuştur (39). Katılımcılara gerçekçi ve güvenilir bir ortam sunar. Simülasyonda gerçek hayat durumları taklit edilerek bilişsel, duyuşsal ve psikomotor becerilerin gelişmesini sağlamaktadır (40). Simülasyon algılanması zor konularda, riskli ve pahalı bazı materyallerin, olayların canlandırılarak gösterilmesine olanak sağlamaktadır. Sağlık bakımı eğitiminde simülasyon;
- Basit teknikleri ve prosedürleri öğrenmek, uygulamak ve yeterlilik kazanma amacıyla düşük özellikli simülatörler,

- Vaka çalışmalarında bilgi elde etmek, bilgiye ulaşma yetkinliğini değerlendirmek, klinik bilgi ve eleştirel düşünme becerileri için geribildirim almak amacıyla bilgisayar destekli simülasyonlar,

- Ultrason, bronkoskopi, laparoskopik cerrahi gibi klinik ortamların taklit edilmesinde bilgisayarla entegre, gerçekliği olan ses, dokunma ve gerçek araçları bulunan kompleks fonksiyonların öğrenilmesi için simülasyonlar,

- Öğrencinin eylemlerine gerçekçi fizyolojik cevap vermesi için programlanabilir, bilgisayarlı bütün vücut mankeni içeren, simüle edilen karmaşık ve yüksek riskli klinik durumlar için kullanılan bütünleşik simülasyonlar (41).

Simülasyonun öğrenmede kullanımını artıran elementler; tıbbi bilginin artması, sağlık eğitimdeki değişimler, hasta güvenliğinin önemli olması, öğrencinin hazır bulunması, tekrarlanabilir olması ve simülasyonun gerçekçilik düzeyi olarak sayılabilir. Hemşirelik eğitiminde hasta bakımını 
geliştirmesi ve hasta güvenliğini sağlaması

nedeniyle birçok yararı bulunmaktadır. Bunlar;

klinik ortam gerçek şekilde canlandırılabilir;

eleştirel düşünme, klinik karar verme ve problem

çözme becerisinin gelişmesini desteklemektedir.

Ayrıca hemşirelik öğrencilerine aktif öğrenme

şans1 sunulmaktadır (39). Simülasyonun

dezavantajları; birebir klinik ortamdaki

öğrenmenin sağlanamaması, öğrenci bu tekniği

kullanırken anksiyete yaşayabilmesi, eğiticinin

senaryo oluştururken daha fazla iş yüküne sahip

olması ve kurum için çok yüksek maliyet

gerektirmesidir (42).

\section{SONUÇ}

Değişen ve ilerleyen teknoloji ile birlikte

öğrencilerin farklı stillerde öğrenme ihtiyaçları

doğmuştur. Özellikle sağlık eğitimi alanında

öğrencilerin bilgi düzeylerinin arttırmak için sağlık

eğiticileri farklı eğitim metotlarını uygulamaları

gerekmektedir. Elektronik Öğrenme (E-Öğrenme),

Artırılmış Gerçeklik (AG), Sanal Gerçeklik (SG),

Yapay Zeka, Bulut Bilişim, QR Kod, Simülasyon

uygulamaları ile öğrenciler için farklı öğrenme

seçenekleri sunmaktadır. Ayrıca eğitimcilerin de güncel bilgiye ulaşması ve teknolojiyi öğretim amacıyla kullanıp, öğrenmesi önemlidir.

\section{KAYNAKLAR}

1. Yardımcı SE. Öğrenme Yaklaşımları, Bilişsel Sınav Kaygısı ve Sosyal Destek Algısı İlişkilerinin Çok Yönlü İncelenmesi: Üniversite Öğrencilerinde Bir Araştırma. Yüksek Lisans Tezi, Fırat Üniversitesi, Sosyal Bilimler Enstitüsü, Elazı̆̆ 2020.

2. Adnan M, Boz-Yaman B. Mühendislik öğrencilerinin e-öğrenmeye dair beklenti, hazır bulunuşluk ve memnuniyet düzeyleri, Turkish Journal of Computer and Mathematics Education, 2017; 8(2), 218-243.

3. Ansong E, Boateng R. Determinants of e-learning adoption in universities: evidence from a developing country, Journal of Educational Technology Systems, 2017; 46(1), 30-60.

4. Yılmaz R, Sezer B, Yurdugül H. Üniversite öğrencilerinin eöğrenmeye hazır bulunuşluklarının incelenmesi: Bartın Üniversitesi örneği, Ege Eğitim Dergisi, 2019; 20(1), 180-195.

5. Wu F, Huang L, Zou R. The design of intervention model and strategy based on the behavior data of learners: A learning analytics perspective, Hybrid Learning: Innovation in Educational Practices, 2015; 9167, 294-301.

6. Telli SG, Altun D. Coronavirüs ve çevrimiçi (online) eğitimin önlenemeyen yükselişi, Üniversite Araştırmaları Dergisi, 2020; 3(1), 25-34.

7. Bozkurt A. Bağlantıcı Kitlesel Açık Çevrimiçi Derslerde Etkileşim Örüntüleri ve Öğreten-Öğrenen Rollerinin Belirlenmesi. Doktora Tezi. Anadolu Üniversitesi, Sosyal Bilimler Enstitüsü, Eskişehir 2016.

8. Wei X, Weng D, Liu Y, Wang Y. Teaching based on augmented reality for a technical creative design course, Computers \& Education, 2015; 81, 221-234.

9. Khan T, Johnston K, Ophoff J. The impact of an Augmented Reality application on learning motivation of students, Advances in HumanComputer Interaction, 2019.

10. Ersoy H, Dumaz E, Öncü S. Artırılmış gerçeklik ile motivasyon ve başarı: deneysel bir çalışma, Öğretim Teknolojileri \& Öğretmen Eğitimi Dergisi, 2016; 5(1).

11. Tepe T. Eğitim teknolojilerinde yeni eğilimler: sanal gerçeklik uygulamalar1, In 10th International Computer and Instructional Technologies Symposium, 2016.

12. Wu HK, Lee SWY, Chang HY, Liang JC. Current status, opportunities and challenges of augmented reality in education, Computers \& Education, 2013; 62, 41-49.

13. Topuz Y, Özdener N. Tıp eğitimde sanal gerçeklik teknolojisi. Değişen Dün, 2018; 225.

14. Kavanagh S, Luxton-Reilly A, Wuensche B, Plimmer BA. Systematic review of virtual reality in education, Themes in Science and Technology Education, 2017; 10(2), 85-119.

15. Bastiaens T, Wood L, Reiners T. New landscapes and new eyes: The role of virtual world design for supply chain education, Ubiquitous Learning, 2014; 6(1), 37-49.

16. Demirezen B. Artırılmış gerçeklik ve sanal gerçeklik teknolojisinin turizm sektöründe kullanılabilirliği üzerine bir literatür taraması, Uluslararası Global Turizm Araştırmaları Dergisi, 2019; 3 (1), 1-26.

17. Avcı AF, Taşdemir Ş. Artırılmış ve sanal gerçeklik ile periyodik cetvel öğretimi, Selçuk-Teknik Dergisi, 2020; 18(2), 68-83.

18. Demirci Ş. Sağlık hizmetlerinde sanal gerçeklik teknolojileri, İnönü Üniversitesi Sağlık Hizmetleri Meslek Yüksek Okulu Dergisi, 2018; 6 (1), 35-46.

19. Lee EAL, Wong KW. Learning with desktop virtual reality: low spatial ability learners are more positively affected, Computers \& Education, 2014; 79: 49-58.

20. Arslan K. Eğitimde yapay zekâ ve uygulamaları, Batı Anadolu Eğitim Bilimleri Dergisi, 2020; 11 (1), 71-88.

21. Popenici SA, Kerr S. Exploring the impact of artificial intelligence on teaching and learning in higher education, Research and Practice in Technology Enhanced Learning, 2017; 12(1), 22. 
22. Holmes W, Bialik M. Fadel C. Artificial intelligence in education: Promises and implications for teaching and learning, Boston, MA: Center for Curriculum Redesign, 2019.

23. Ma Y, Siau KL. Artificial intelligence impacts on higher education, MWAIS Proceedings, 2018; 42(5).

24. Marston S, Li Z, Bandyopadhyay S, Zhang J, Ghalsasi A. Cloud computing: The business perspective, Decision Support Systems, 2011; 51(1), 176-189.

25. Armutlu H, Akçay M. Bulut bilișim uygulamalarında amazon web servisleri hizmetlerinin ve javascript dilinin birlikte kullanımı, XVII. Akademik Bilişim Konferansı, Eskişehir 2015.

26. Aktepe Ç. Lojistik İşletmelerinde Bulut Bilişim Uygulamalarının Değerlendirilmesi. Yüksek Lisans Tezi, Dokuz Eylül Üniversitesi, Sosyal Bilimler Enstitüsü, İzmir 2015.

27. Demirkaya H, Sarpel E. Eğitim ve geliştirme uygulamalarında yeni nesil bilişim teknolojilerinden sanal gerçeklik, bulut bilişim ve yapay zeka. Karadeniz Uluslararası Bilimsel Dergi, 2018; (40), 231-245.

28. Park EW, Lee H, Yun. EK. (2019). Development and evaluation of a Quick Response code-based nursing education program for operating and recovery room nurses, CIN: Computers, Informatics, Nursing, 2019; 37(11), 599-605.

29. Çataloğlu E, Ateşkan A. QR (Quick Response) kodunun eğitim ve öğretimde kullanımının örneklenmesi, Elementary Education Online, 2014; 13(1).

30. Downer T, Oprescu F, Forbes H, Phillips N, McTier L, Lord B, Simbag $\mathrm{V}$. Enhancing nursing and midwifery student learning through the use of QR codes. Nursing education perspectives, 2016; 37(4), 242-243.

31. Rikala J, Kankaanranta M. (2012). The Use of Quick Response Codes in the classroom, In mLearn 2012; 148-155.

32. Dönmez Usta N, Turan Güntepe E. Öğrenme ortamında qr kod destekli materyallerin kullanımı, Abant İzzet Baysal Üniversitesi Eğitim Fakültesi Dergisi, 20190; 19(3), 923-935.

33. Karahan E, Canbazoğlu Bilici S. QR kodların Fen Eğitimine entegresyonu: Öğretmen görüşleri ve öneriler, Necatibey Eğitim Fakültesi Elektronik Fen ve Matematik Eğitimi Dergisi, 2017; 11 (1), 433-457.

34. Karia CT, Hughes A, Carr S. Uses of quick response codes in healthcare education: a scoping review, BMC Medical Education, 2019; 19(1), 456.

35. Lin KY, Yang YC, Lai CY. The use of quick response codes for teaching pharmacology to college nursing students in Taiwan, CIN: Computers, Informatics, Nursing, 2017; 35(3), 152-157.

36. Shustack L. Virtually engaging millennial nursing students through QR codes, Journal of Nursing Education, 2018; 57(11), 699-700.

37. Graván PR, Gutiérrez ÁM. Social networks as tools for acquiring competences at university: QR codes through Facebook, International Journal of Educational Technology in Higher Education, 2014; 11(2), $27-40$.

38. Aul K, Johnston L. Engaging undergraduate nursing students with barcode scanning in an oncology course, Journal of Nursing Education, 2018; 57(7), 451-452.

39. Durmaz Edeer, A., Dicle, A. Hemşirelik eğitiminde simülasyon kullanımı ve simülasyon tipleri, Koç Üniversitesi Hemşirelikte Eğitim ve Araştırma Dergisi, 2015; 12(2), 121-125.

40. Uslu Y, Ünver V, Kocatepe V, Karabacak Ü. Hemşirelik eğitiminde simülasyon tasarımı örneği: Güvenli kemoterapi ilaç uygulamas1, Journal of Nursing, 2019; 27(3), 304-313.

41. Şahiner NC, Türkmen AS, Kuğuoğlu S. Ülkemizde çocuk hemşireliği eğitiminde simülasyon nerede?, Türkiye Klinikleri Pediatric NursingSpecial Topics, 2017; 3(1), 39-43.

42. Göriş S, Bilgi N, Korkut Bayındır S. Hemşirelik eğitiminde simülasyon kullanımı. Düzce Üniversitesi Sağlık Bilimleri Enstitüsü Dergisi, 2014; 1(2), 25-29. 